\author{
Review Article \\ www.ijrap.net
}

\title{
GLOBAL STATISTICAL ANALYSIS OF DIABETES MELLITUS WITH STRESS ON PREVALENCE IN ASIA AND SPECIFICALLY INDIA: A CRITICAL AND CLINICAL OVERVIEW
}

Vijaya Lakshmi P, Sudheerbabu I.

Sir C.R. Reddy College of Pharmaceutical Sciences, Eluru, Andhra Pradesh, India

Received on: 29/12/17 Accepted on: 12/02/18

\author{
*Corresponding author \\ E-mail: sravya1996penmetsa@gmail.com
}

DOI: $10.7897 / 2277-4343.09363$

\begin{abstract}
Diabetes mellitus is a chronic metabolic non-communicable disease which has been raising rapidly in middle and low-income countries. The number of people with diabetes has increased from 108 million in 1980 to 422 million in 2014 and it has been rising rapidly, resulting in various complications like blindness, kidney failure, heart attacks, stroke and lower limb amputation. Almost half of diabetics are from China, India and USA. In 2015, an estimated 1.6 million deaths were by diabetes alone and another 2.2 million deaths were by high blood glucose levels. Almost half of the deaths attributable to high blood glucose occur before the age of 70 years, placing diabetes the seventh leading cause of death. In India $8.7 \%$ of people are diabetic and $10.3 \%$ are showing prediabetic symptoms which implies that this population is on verge to develop diabetes in near future. Diabetes can be treated and its consequences can be avoided or delayed with diet, physical activity, medication, regular screening and treating complications.
\end{abstract}

Keywords: Prediabetes, Impaired glucose tolerance, Prevalence, Staple food, Epidemiology.

\section{INTRODUCTION}

Diabetes is a most common non-communicable disease globally, in which the blood glucose levels are increases abnormally. With type1, in which the body does not make enough insulin \& type 2 (more prevalent) in which the body, do not use insulin well. The presence of high blood sugar than normal, but not enough to the body is called as diabetes and prediabetes. Having prediabetes may put the person at greater risk of type 2 diabetes, heart disease and stroke ${ }^{1}$.

Type 1 and type 2 diabetes were identified as separate conditions for the first time by the Indian physicians Sushrutha \& Charaka in 400-500 BCE as type 1 associated with youth and type 2 with obesity. The first known symptoms of diabetes were identified in $1552 \mathrm{BCE}$, i.e. frequent urination and also ants are attracted to the urine of people who had this disease. In the 1700s and 1800s, Physicians began to realize that the dietary changes could help manage diabetes ${ }^{2}$.

Over time, high blood sugar can seriously compromise every major organ system in the body causing heart attacks, nerve damage, kidney failure, impotence, blindness, foot infections that may also lead to amputations ${ }^{3}$.

Worldwide the estimated number of adults with diabetes in the year 1980 was 108 million \& in 2000 was 171 million \& in 2007 was found to be 246 million of these $80 \%$ are from developing countries, the largest numbers on the Indian subcontinent and Asia of which $85-95 \%$ are type 2 diabetes. It is estimated that nearly 380million adults worldwide will have diabetes by 2025 . The number of diabetes has gone up from 108 million in1980 to 422 million in 2014. Due to various factors, the prevalence of diabetes is more in men than in women, but there are more women suffering with diabetes than men.

\section{EPIDEMIOLOGY OF DIABETES ACROSS THE WORLD}

Based on the available statistical data of 2014, from world health organisation, 422 million adults are living with diabetes mellitus. Previous 2013 estimates from International Diabetes Federation put the number at 381 million people having diabetes of which $80-85 \%$ is type 2 diabetes. Almost half of the people with diabetes belong to China, India and USA. The WHO estimates, diabetes has resulted in 1.5 million deaths in 2012, making it the 7th leading cause of death.

\section{Diabetes in North America}

\section{Canada}

About 2.4 million Canadians have been diagnosed with diabetes in 2009. The count has increased by $70 \%$ over a decade from 1999 to 2009 . The highest prevalence was among the $35-40$ years age group, due to increased rates of overweight and obesity. The Public Health Agency of Canada estimates if this trend continues, the number of Canadians living with diabetes will reach up to 307 million by $2019^{4}$. 


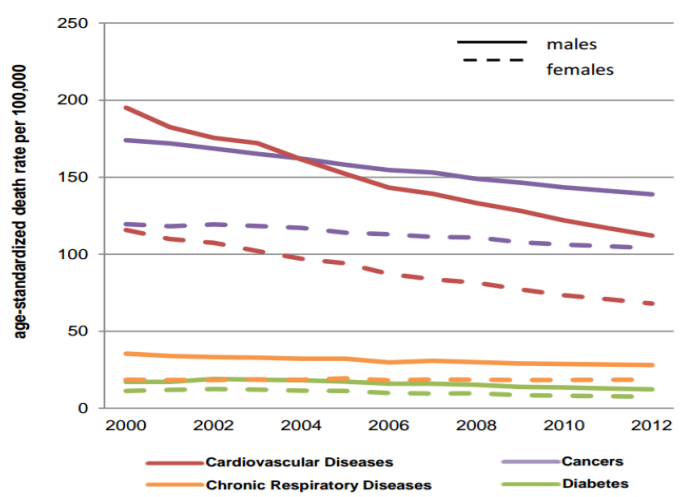

Figure 1: Graphical representation of age standardised death rates v/s year

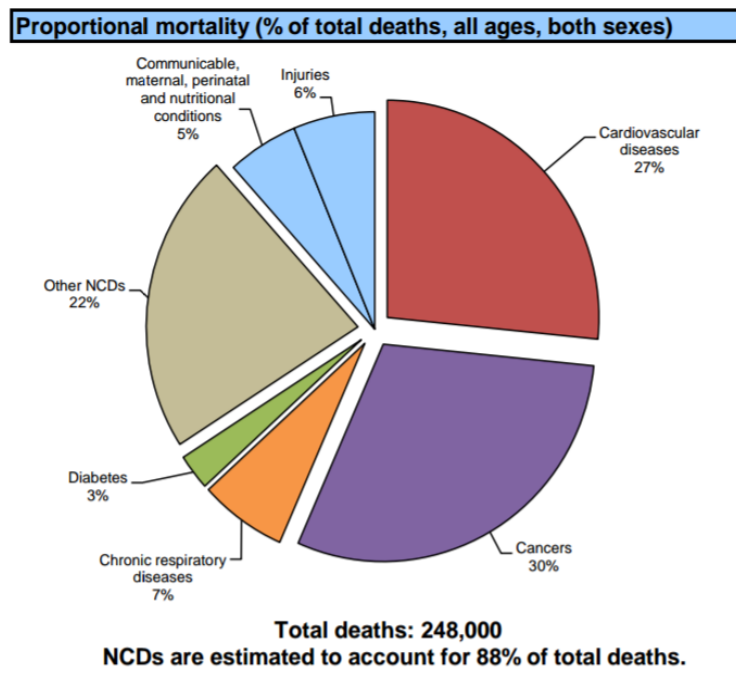

Figure 2: Proportional Mortality Percent

\section{Diabetes in United States of America}

An estimated 30.3 million people i.e. $9.4 \%$ of the US population had diabetes in 2015. This included 30.2 million (12.2\%) of total adults aged 18 years or above of which 7.2 million (23.8\%) are not aware that they are diabetic.

The percentage of people affected with diabetes increased with age, reaching as high as $25.2 \%$ among those aged $65 \mathrm{yrs}$ and older. An estimated $33.9 \%$ (84.1 million) of US adults aged 18 years or older had prediabetes in 2015. Nearly half of the adults (48.3\%) aged 65 years or older had prediabetes. According to 2011-2014 data there are more men $(36.6 \%)$ than women $(29.3 \%)$ with prediabetes ${ }^{5}$.

According to the 2016 statistics, it was found that the diabetes prevalence in the country went from $9.2 \%$ in 2012 to $9.4 \%$ in 2016. With women $(10.3 \%)$ having higher diabetes rate than men $(8.4 \%)$. This trend is observed both in urban $(10.5 \%$ in women and $8.2 \%$ in men) and rural areas $(9.5 \%$ in women and $8.9 \%$ in men). Higher diabetes prevalence is observed among men aged 60-69 years old $(27.7 \%)$ than in women and $70-79$ years old $(29.8 \%)$. The present diabetic population in Mexico is 8.5 million $^{67}$.

\section{Age-Adjusted Prevalence of Diagnosed Diabetes Among US Adults 2015}

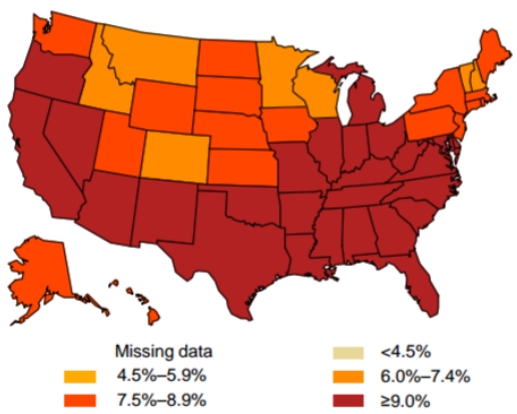

Figure 3: Age adjusted prevalence of diagnosed diabetes among US adults

\section{Diabetes in Europe}

About 60 million people in the European region are diabetics, of which about $10.3 \%$ are men and $9.6 \%$ are women aged greater than 25 years. Also 3.8 million people in the united kingdom have diabetes mellitus, it was predicted this might increase up to 6.2 million by 2035/2036.Among the European countries, Turkey(14.01\%) ranks one in diabetes followed by Portugal (13.09),Bosnia and Herzegovina (12.1), Montenegro (12\%) ,Serbia (11.96\%), Germany (11.52\%), Macedonia(11.4), Malta $(10.69 \%)$, Spain $(10.58 \%)^{8}$.

\section{Turkey}

According to Turkish diabetes foundation, $15 \%$ of Turkish adults are diabetic and the rate is increasing significantly. In last 10 years it raised from $7.6 \%$ to $13.2 \%$. The diabetic males accounting $12.2 \%$, alongside $14.2 \%$ of females, leading to a total average $13.2 \%$ of diabetics. The diabetic deaths noted in the age group 30-69 are1030 (in males) and 1210 (in females). In the age group greater than 70 years it raised up to 2280 in males \& 3790 in females. Diabetes constitutes a total of $2 \%$ of deaths that occur in all age groups ${ }^{9}$.

Proportional mortality ( $\%$ of total deaths, all ages)*

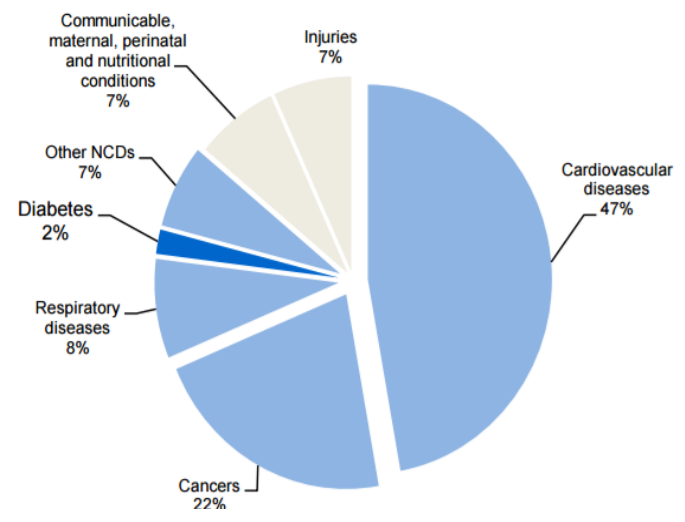

Figure 4: total \% of deaths related to various diseases in 2016 
Trends in age-standardized prevalence of diabetes

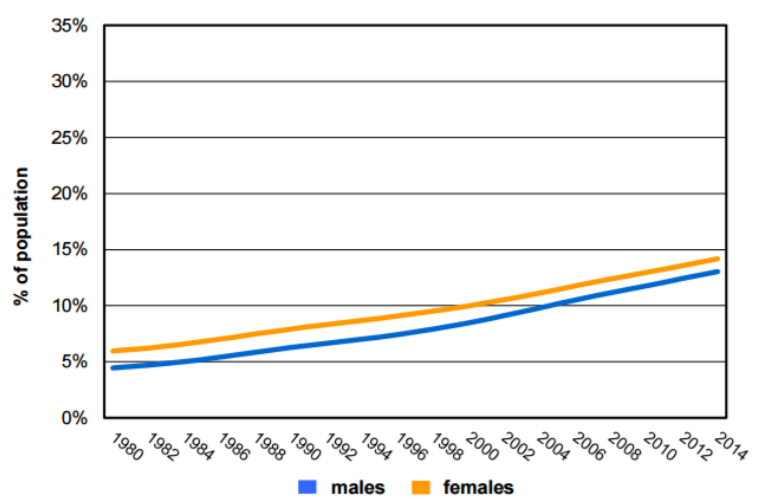

Figure 5: Graphical representation of prevalence of diabetes in males and females in \% population

\section{Portugal}

According to the national diabetes observatory of Portugal and WHO, prevalence of diabetes in males $-10.7 \%$ and females- $7.8 \%$ in between the age group 20-79 years and a total of $9.2 \%$ of population are diabetic. Diabetes constitute of about $5 \%$ of total deaths that occur in all age groups. The prevalence of diabetes has been increasing readily in male's from $1980-2014$, ranging $3-11 \%$ where as in females it is a little lower comparatively i.e. $4-8 \%{ }^{10}$.

\section{Proportional mortality ( $\%$ of total deaths, all ages)}

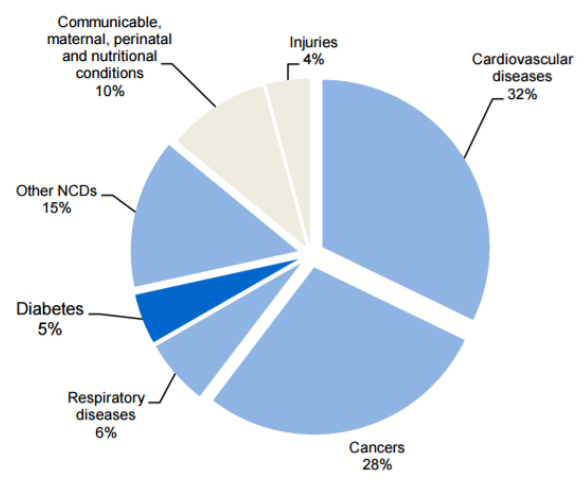

Figure 6: Total \% of deaths due to various diseases in Portugal in 2016

\section{Trends in age-standardized prevalence of diabetes}

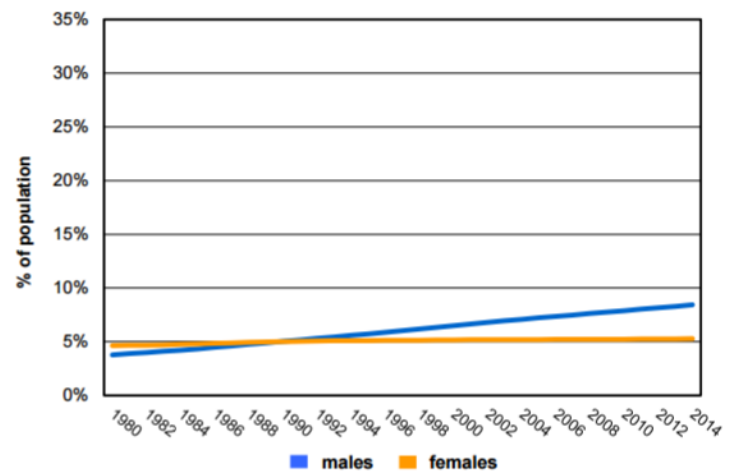

Figure 7: Prevalence of diabetes in \% population (of males and females) $v / s$ years

\section{Diabetes in South America}

The South and Central America are inhabited with a population of 467.6 million and $64 \%$ of which are within the age group 2079 years, the prevalence of diabetes in this region is $8 \%$ and increased to $9.4 \%$ in 2015 i.e. 29.6 million people and is expected to reach $9.8 \%$ by 2035 . On an average $24 \%$ of the adult cases are undiagnosed, but in some countries, it is as high as $50 \%{ }^{11}$.

In 2015,247500 adults died of diabetes. Over $42.7 \%$ of these deaths are in people under the age of 60 . And half of the deaths are from Brazil.

\section{Diabetes in Brazil}

According to the geographical statistics, there are about 190,755 million inhabitants in Brazil. According to International Diabetes Federation, 11.9 million individuals between the age group 20-79 years are diagnosed as diabetic, Brazil ranked $5^{\text {th }}$ in diabetes in whole world. The cities Ribeirao Preto and Sao Carlos, both in the state of São Paulo and Porto Alegre in the state of Rio Grande, Paraíba do sul showed prevalence rates of $12.1 \%, 13.5 \%$ and $12.4 \%$ respectively ${ }^{12}$.

According to the WHO-Diabetes country profile 2016, almost $7.4 \%$ of males are diabetic and $8.8 \%$ of females are diabetic with a total average of $8.1 \%$. Diabetes owns $6 \%$ of total deaths of all ages. The prevalence of diabetes in Brazil has been increasing since 1990-2016 lying between 5-10\%.

Trends in age-standardized prevalence of diabetes

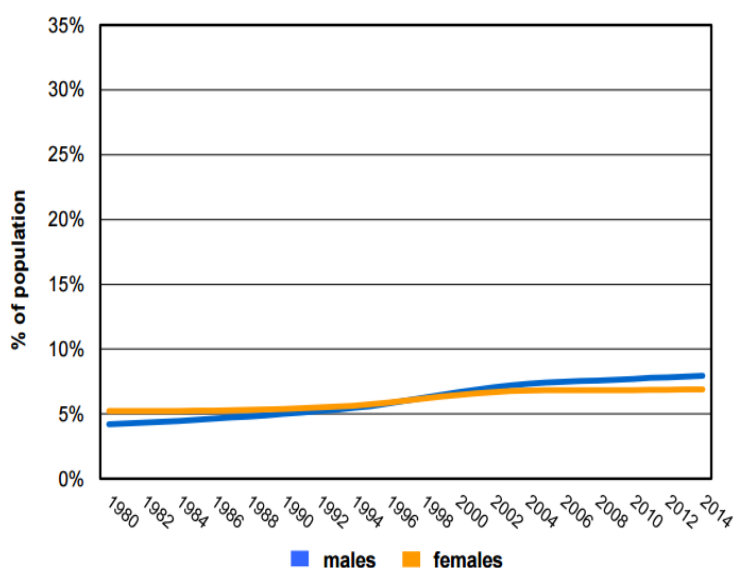

Figure 8: Prevalence of diabetes in males and females from 19802014

\section{Proportional mortality ( $\%$ of total deaths, all ages)}

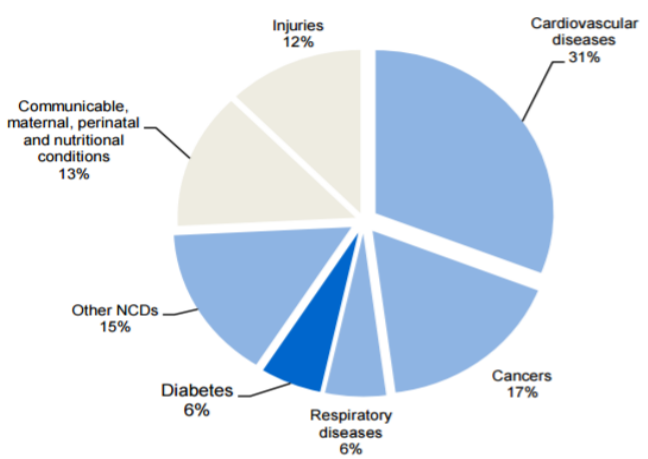

Figure 9: Representation of total \% deaths in pie diagram 


\section{Diabetes in Venezuela}

In Venezuela, the prevalence of diabetes is $7.7 \%$ and prediabetes is $11.2 \%$ and it was the $5^{\text {th }}$ leading cause of death in $2012 .{ }^{13}$ According to the WHO-diabetes country profiles 2016, the prevalence of diabetes is $9.1 \%$ in males, $8.5 \%$ in females and a total average of $8.8 \%$ of people suffer with diabetes; the percentage of deaths in all ages due to diabetes is $7 \%$ of total deaths. The prevalence of diabetes has been increasing from 5$19 \%$ in $1990-2016$.

\section{Trends in age-standardized prevalence of diabetes}

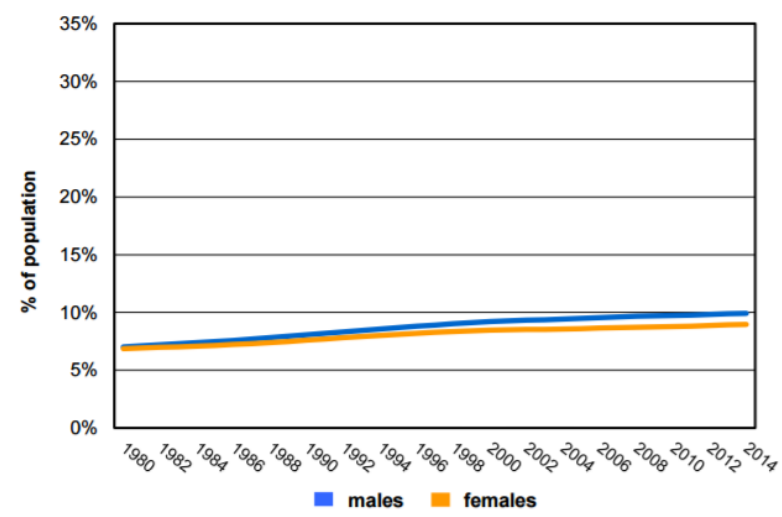

Figure 10: Graphical representation of prevalence of diabetes in Venezuela from 1980-2014

\section{Proportional mortality ( $\%$ of total deaths, all ages)}

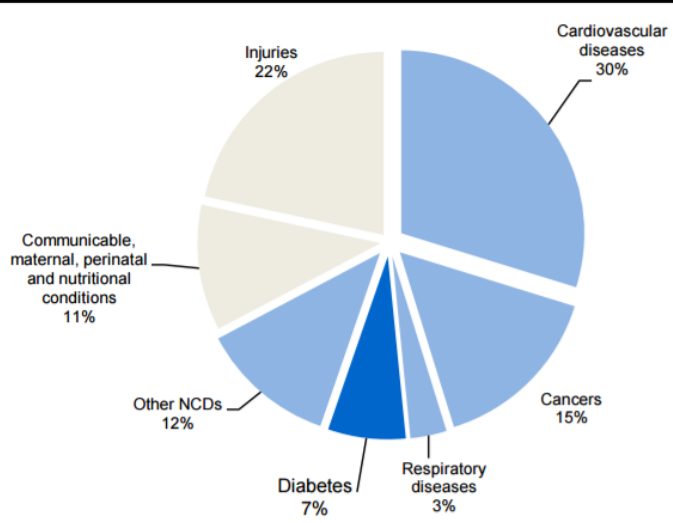

Figure 11: Representation of total deaths due to various diseases in pie chart form

\section{Diabetes in Africa}

The number of people with diabetes in Africa remains uncertain, although the estimate of 2000 put the figure at 7.5 million diabetic's adults between 20-79 years of age and now it is much higher.

The number of people living with diabetes has jumped from 4 million in 1980 to 25 million in 2014.

Although, Type 1 diabetes is rare in many areas, but now its prevalence is increased. Impaired glucose tolerance has turned problematic and exceeds $30 \%$ in many south African countries ${ }^{14}$

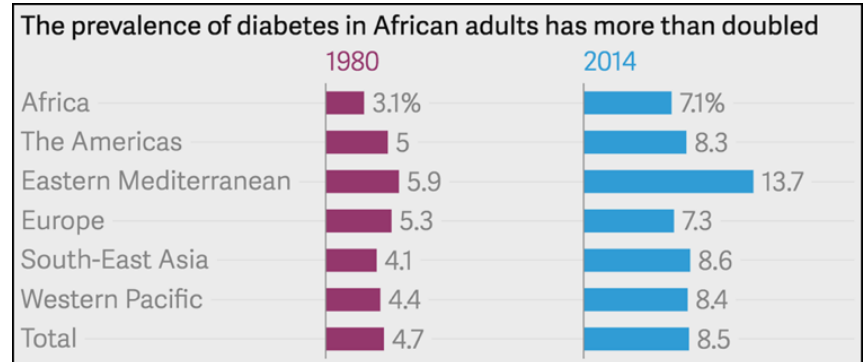

Figure 12: Prevalence of diabetes\% in 1980 \& 2014

\section{Diagnosed Diabetes among Adults Age 20 years and older, by Race/Ethnicity, 2007-2009}

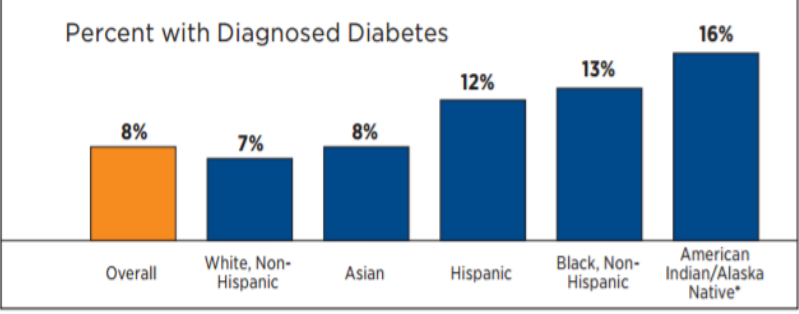

Figure 13: Diagnosed diabetes among adults age 20 years and older, by race/ethnicity, 2007-2009

Table 1: The World Health Organisation estimated the following diabetes populations by country for 2000 , and 2030

\begin{tabular}{|c|c|c|}
\hline Country & 2000 & 2030 \\
\hline Algeria & 426,000 & $1,203,000$ \\
\hline Angola & 51,000 & 140,000 \\
\hline Benin & 87,000 & 266,000 \\
\hline Botswana & 25,000 & 45,000 \\
\hline Burkina Faso & 124,000 & 388,000 \\
\hline Burundi & 26,000 & 72,000 \\
\hline Cameroon & 70,000 & 171,000 \\
\hline Cape Verde & 7,000 & 24,000 \\
\hline CAR & 18,000 & 46,000 \\
\hline Chad & 97,000 & 269,000 \\
\hline Comoros & 4,000 & 15,000 \\
\hline Congo & 14,000 & 39,000 \\
\hline Côte d'Ivoire & 264,000 & 636,000 \\
\hline DR Congo & 291,000 & 910,000 \\
\hline Eq. Guinea & 8,000 & 21,000 \\
\hline Eritrea & 65,000 & 142,000 \\
\hline Ethiopia & 796,000 & $1,820,000$ \\
\hline Gabon & 8,000 & 14,000 \\
\hline Gambia & 22,000 & 61,000 \\
\hline Ghana & 302,000 & 851,000 \\
\hline Guinea & 34,000 & 89,000 \\
\hline Guinea-Bissau & 17,000 & 44,000 \\
\hline
\end{tabular}




\begin{tabular}{|c|c|c|}
\hline Country & 2000 & 2030 \\
\hline Kenya & 183,000 & 498,000 \\
\hline Lesotho & 31,000 & 42,000 \\
\hline Liberia & 40,000 & 154,000 \\
\hline Madagascar & 100,000 & 301,000 \\
\hline Malawi & 65,000 & 118,000 \\
\hline Mali & 140,000 & 405,000 \\
\hline Mauritania & 34,000 & 103,000 \\
\hline Mauritius & 111,000 & 233,000 \\
\hline Mozambique & 133,000 & 291,507 \\
\hline Namibia & 25,000 & 60,000 \\
\hline Niger & 108,000 & 382,000 \\
\hline Nigeria & $1,707,000$ & $4,835,000$ \\
\hline Rwanda & 30,000 & 77,000 \\
\hline Sao Tome & 1,000 & 2,000 \\
\hline Senegal & 143,000 & 421,000 \\
\hline Seychelles & 8,000 & 19,000 \\
\hline Sierra Leone & 65,000 & 178,000 \\
\hline South Africa & 814,000 & $1,286,000$ \\
\hline Swaziland & 13,000 & 21,000 \\
\hline Togo & 64,000 & 184,000 \\
\hline Uganda & 98,000 & 328,000 \\
\hline UR Tanzania & 201,000 & 605,000 \\
\hline Zambia & 70,000 & 186,000 \\
\hline Zimbabwe & 108,000 & 265,000 \\
\hline Total & $7,020,000$ cases & $18,234,000$ cases \\
\hline
\end{tabular}

\section{Diabetes in Australia}

Around 1.7 million Australians are with diabetes, which include 1.2 million of diagnosed and nearly 500,000 undiagnosed cases. More than 100,000 Australians developed diabetes in the past year. 280 Australians develop diabetes every day and that is one person every five minutes.

Type 1 diabetes accounts for $10 \%$ of total diabetic population in Australia and type 2 of about $85 \%$. Australia has the $7^{\text {th }}$ highest prevalence and $6^{\text {th }}$ highest incidence of type 1 diabetes in children aged $0-14$ years.

Diabetes is more prevalent in South Australia and the northern territory; it was found that 58 people per 1000 were registered as diabetic in South Australia and Northern Territory was close behind with 56 people per 1000 .Almost $37 \%$ of diabetic people live in Australia 161718

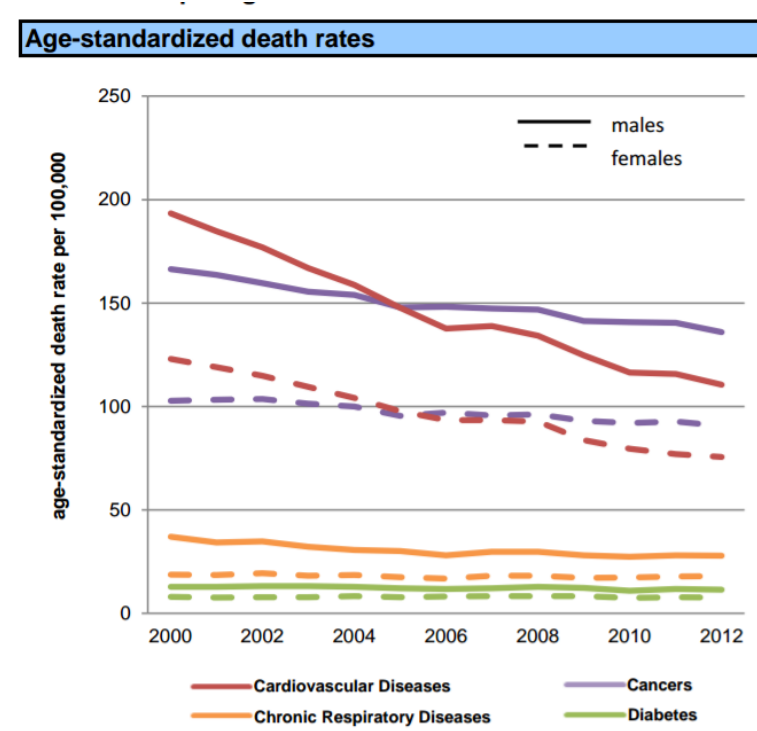

Figure 14: Graphical representation of age standardised deaths from 2000-2012

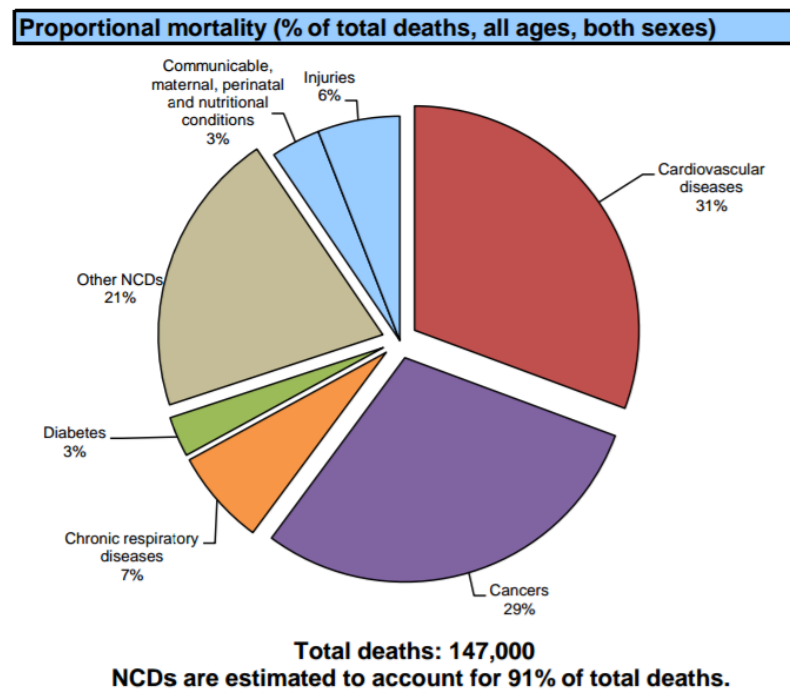

Figure 15: Percentage of total deaths in Australia in 2016

\section{Diabetes in Asia}

There are now 422 million people living with diabetes, according to International Diabetes Federation (IDF). More than half are from Asia and the Western pacific, where $90-95 \%$ of cases are classed as Type- 2 .

\section{Diabetes in china}

China is leading the world, with the disease now affecting more than $98.4 \%$ (110 million) people or about $10 \%$ of the total world population there is a dramatic increase from about less than $5 \%$ in 1980. 
Number of people with diabetes

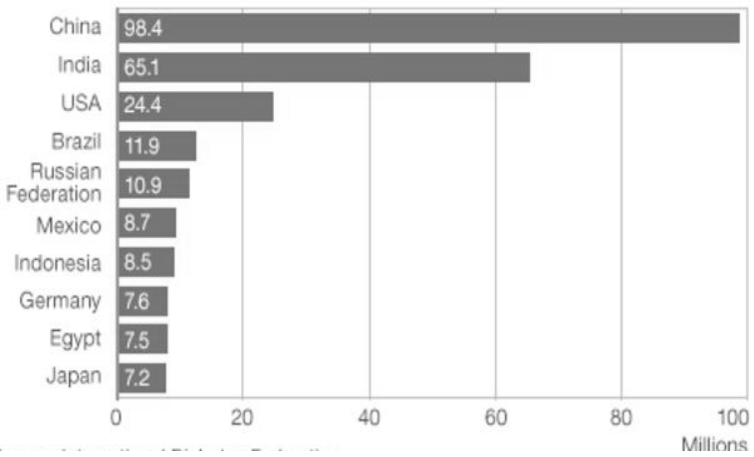

Figure 16: Diabetic population of various countries in millions

Almost one in ten of Chinese adults have diabetes. A 2010 study estimated that more than 92 million Chinese adults have the disease, with another 150 million showing early symptoms. The incidence is rapidly increased to a $30 \%$ in 7 years. According to 2016 statistics, one in three of world's adults with diabetes are from china, i.e. almost $10 \%$ of all adults in china (110 million people) currently living with diabetes and this number may be increased to 150 million by 2040 . India is closely trailing China, with an estimated 65.1 million diabetics, which is more than $7.1 \%$ of the adult population. The average age onset is 42.5 years. Nearly 01 million Indians die due to diabetes every year. According to the Indian Heart Association, the diabetics will increase to 109 million by 2035 . The high incidence is attributed to a combination of genetic susceptibility, adoption of a highcalorie diet, low activity life style. ${ }^{19} 20$

\section{Diabetes prevalence in India}

India had 69.2 million people living with diabetes $(8.7 \%)$ as per 2015 data. Of these, it remained undiagnosed in almost 36 million people. Number of diabetes deaths in India between the ages 3069 is 79,500 in males and 51700 in females. Meghalaya has the lowest prevalence of diabetes prevalence at $4.5 \%$, while Chandigarh has the highest at $13.6 \%$ followed by Punjab at 9.8\%. Prediabetes prevalence is also high in Chandigarh at $14.6 \%$ and the lowest at Mizoram at 5.8\%. A large community based study involving over 15,000 adults from 14 states and a union territory in the country has revealed that the average prevalence of diabetes in these states is over $7.3 \%$.

The prevalence varied from $4.3 \%$ of Bihar population, to $10.4 \%$ in Tamil Nadu, Chandigarh was found to have a prevalence of $13.6 \%$, Punjab (9.8\%). This shows that the economically more developed states had a higher prevalence than economically less developed states. The prevalence of diabetes was lower in the northeast states compared with other states.

The prevalence of prediabetes in all 14 states and union territory was found to be $10.3 \%$.it varied from $6 \%$ (Mizoram) to $14.7 \%$ (Tripura). The prevalence of prediabetes implies the percentage of population prone to develop diabetes in near future.

The undiagnosed diabetes is almost $45 \%$, prevalence was higher in urban areas $(11.2 \%)$ compared to rural areas $(5.2 \%)$. The prevalence of diabetes in north east is $5.9 \%$ which is lesser than the other states $(8.3 \%)$. The prevalence of diabetes is higher in the states- Chandigarh, Tamil Nadu and Gujarat which are having high socio-economic status even in the rural areas.

\section{Proportional mortality ( $\%$ of total deaths, all ages) ${ }^{\star}$}

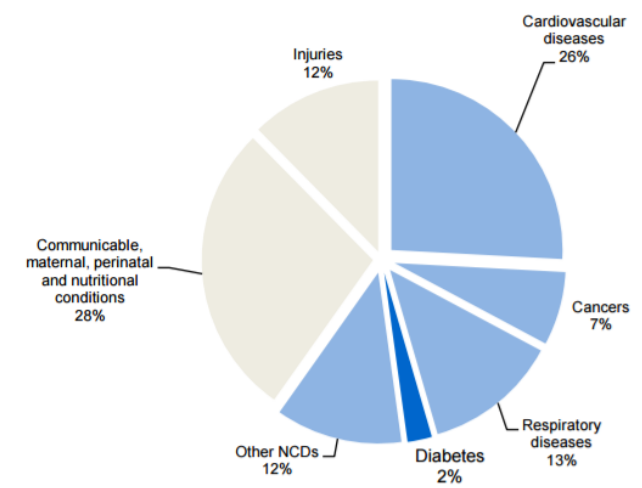

Figure 17: Total deaths $\%$ in all ages based on the cause of death

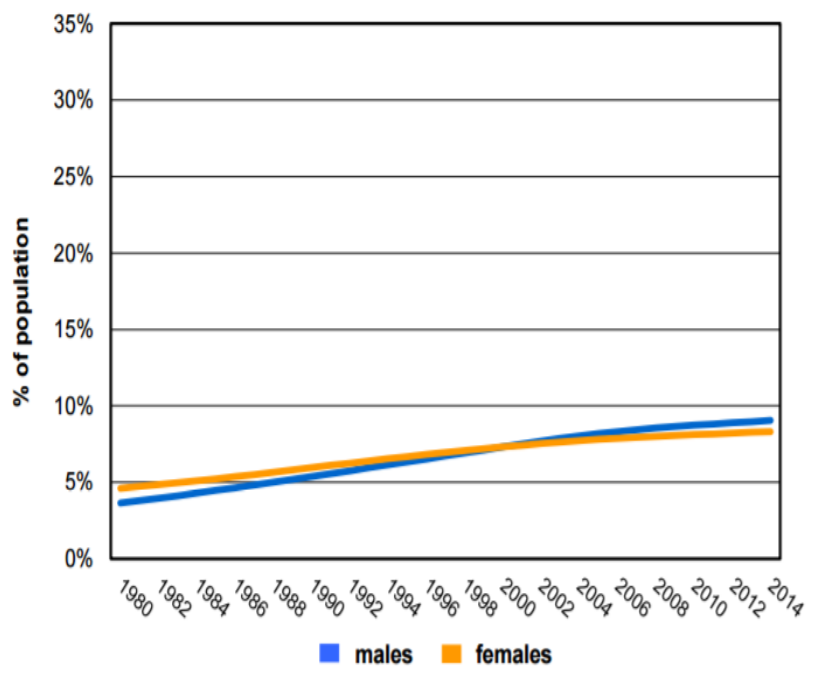

Figure 18: Trends in age standardized prevalence of diabetes

\section{Dietary profile}

The staple food consumed by the urban and rural population in all the four regions is shown below:
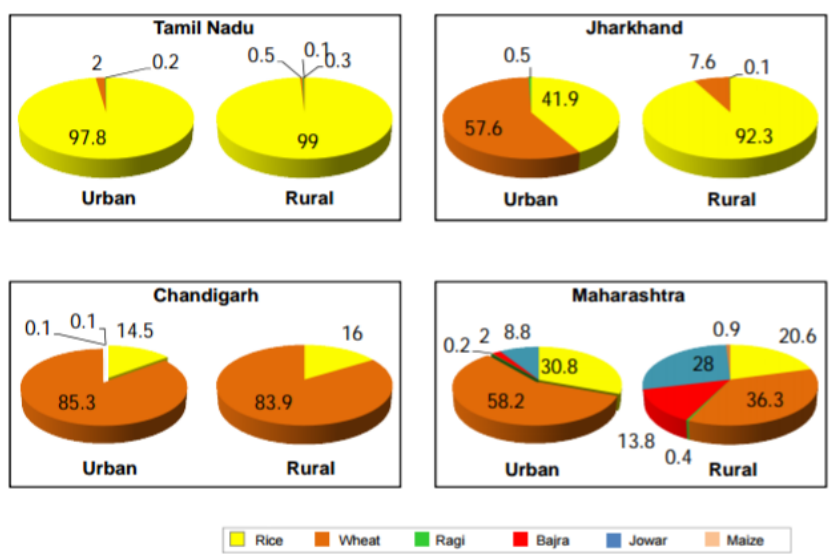

Figure 19: Staple food of the urban and rural population in all the four regions

Rice is the main staple food in Tamil Nadu and rural Jharkhand. Wheat is main staple for both urban and rural Chandigarh. About half of the population in urban Jharkhand and Urban Maharashtra 
consumes wheat as the main staple food. The staple food in rural Maharashtra is varied and comprises of $36.3 \%$ wheat, $28 \%$ Jowar, $20.6 \%$ rice, $13.8 \%$ Bajra, $0.9 \%$ maize and $0.4 \%$ Ragi consumers. The following table shows the major cooking oil of the urban and rural population in all the four regions. In Tamil Nadu, the major oil used for cooking is sunflower oil, followed by palm oil, groundnut oil and gingerly oil. The major cooking oil in Jharkhand is mustard oil. In Chandigarh, in addition to mustard oil, the next major oil used is soybean oil, in Maharashtra, the major oil used is soybean oil, followed by groundnut and sunflower oil ${ }^{21}$.

Table 2: Major cooking oil used in the urban and rural population in all four regions

\begin{tabular}{|c|c|c|c|c|c|c|c|c|}
\hline \multirow[t]{2}{*}{ Cooking Oil } & \multicolumn{2}{|c|}{ TAMIL NADU } & \multicolumn{2}{|c|}{ JHARKHAND } & \multicolumn{2}{|c|}{ CHANDIGARH } & \multicolumn{2}{|c|}{ MAHARASHTRA } \\
\hline & Urban & Rural & urban & rural & urban & Rural & urban & rural \\
\hline Mustard Oil & 0.3 & 0.1 & 90.4 & 98.7 & 65.4 & 81.6 & 4.1 & 0.9 \\
\hline Coconut Oil & 2.3 & 3.2 & 0.2 & 0 & 0 & 0.2 & 0.6 & 0.2 \\
\hline Groundnut Oil & 21.4 & 39.7 & 1.1 & 0.1 & 1.2 & 0.3 & 29.6 & 20.2 \\
\hline Sunflower Oil & 40.0 & 15.9 & 2.3 & 0.1 & 4.2 & 0.5 & 14.9 & 5.3 \\
\hline Soya Bean Oil & 0.2 & 0 & 4.7 & 0.2 & 23.2 & 14.2 & 45.1 & 65.0 \\
\hline Palm Oil & 29.6 & 29.7 & 0.2 & 0.1 & 0.4 & 0.1 & 3.3 & 5.6 \\
\hline Gingelly Oil & 5.4 & 11.2 & 0.3 & 0 & 0.1 & 0 & 0 & 0.1 \\
\hline Others & 0.9 & 0 & 0.8 & 0.7 & 5.4 & 2.9 & 2.5 & 2.7 \\
\hline
\end{tabular}

Table 3: Indicating State/UT wise number of new cases of diabetes detected in 2014-15 \& 2015-16 (till Oct 2015$)^{22}$

\begin{tabular}{|c|c|c|c|}
\hline \multirow[b]{2}{*}{ Sl. No } & \multirow[b]{2}{*}{ States and UT's } & \multicolumn{2}{|c|}{ Patients diagnosed with diabetes at NCD clinics } \\
\hline & & $2014-15$ & 2015-16(till oct,2015) \\
\hline 1 & Andhra Pradesh & 9,139 & 35,461 \\
\hline 2 & Arunachal Pradesh & 1,469 & 2,384 \\
\hline 3 & Assam & 5,052 & 6899 \\
\hline 4 & Bihar & 9,595 & NA \\
\hline 5 & Chhattisgarh & 11,897 & 45833 \\
\hline 6 & Goa & 5,692 & 7,297 \\
\hline 7 & Gujarat & $1,61,578$ & $10,9,340$ \\
\hline 8 & Haryana & 27,185 & 9,205 \\
\hline 9 & Himachal Pradesh & 2,777 & 3,749 \\
\hline 10 & Jammu and Kashmir & 3,701 & 1,763 \\
\hline 11 & Jharkhand & 17,240 & 11,388 \\
\hline 12 & Karnataka & 15,871 & 8,757 \\
\hline 13 & Kerala & 29,768 & 13,435 \\
\hline 14 & Madhya Pradesh & 10,165 & 16,825 \\
\hline 15 & Maharashtra & 53,488 & 41,608 \\
\hline 16 & Manipur & NA & NA \\
\hline 17 & Meghalaya & 190 & 484 \\
\hline 18 & Mizoram & 2,992 & 3,859 \\
\hline 19 & Nagaland & 328 & 375 \\
\hline 20 & Odisha & 17,834 & 34,721 \\
\hline 21 & Punjab & 32,100 & 13,766 \\
\hline 22 & Rajasthan & 67,738 & 31,300 \\
\hline 23 & Sikkim & 937 & 1,325 \\
\hline 24 & Tamil Nadu & NA & 66,896 \\
\hline 25 & Telangana & NA & NA \\
\hline 26 & Tripura & NA & 50 \\
\hline 27 & Uttar Pradesh & 60,459 & 91,937 \\
\hline 28 & Uttarakhand & 645 & 291 \\
\hline 29 & West Bengal & 11,908 & 7,295 \\
\hline 30 & Andaman \& Nicobar & NA & 3,245 \\
\hline 31 & Chandigarh & NA & NA \\
\hline 32 & Dadar \& N.Haveli & NA & NA \\
\hline 33 & Daman \&Diu & NA & NA \\
\hline 34 & Lakshadweep & NA & NA \\
\hline 35 & Delhi & NA & NA \\
\hline 36 & Puducherry & NA & 4,727 \\
\hline & TOTAL & $5,59,718$ & $5,74,215$ \\
\hline
\end{tabular}

\section{CONCLUSION}

The above data suggests that diabetes is a disorder which occurs due to intake of high calorific diet with low activity (sedentary life style). It was also observed that food habits of different parts of the world is also a contributing factor for diabetes. It can be controlled only by sticking to good food regimen, by keeping check on junk food and also by regular physical exercise; as this disease may silently cause major harm to the people in coming years, making it deadlier than other prevalent diseases. 


\section{REFERENCES}

1. World Health Organization(WHO). Global report on Diabetes 2016 [internet]. Available from: www.who.int > diabetes $>$ global-report.

2. Ambady ramchandran and Chamukuttan snehalathamCurrent scenario of diabetes in India https://www.ncbi.nlm.nih.gov/pubmed/20923516

3. World Health Organisation(WHO). World Health Day 2016: Beat Diabetes [internet] Available from: www.searo.WHO.int/india/mediacentre/events/2016/en/

4. Canada Diabetes Association. Diabetes Canada [internet]. Available from: https://www-diabetes.ca

5. Centre for Disease Control and Prevention(CDC). National Diabetes statistics report 2017-10-08. Available from: https://www.cdc.gov/diabetes/data/statistics/statisticsreport.html

6. Mexican observatory on noncommunicable diseases(OMENT). Latest diabetes statistics in mexicoENSANUT2016 Available from:-oment.unal.mx/latestdiabetes-statistics-in-mexico-ensanut-2016/lang-en

7. Centre for Disease Control and Prevention(CDC). Maps of trends in diagnosed diabetes and obesity-April 2017 Available from: http://www.cdc.gov/diabetes/data

8. Newly Diagnosed with Diabetes-Diabetes in Europe/uk Available form: www.diabetes.co.uk/newly-diagnosed.html/

9. Innovating diabetes Care in turkey- the blueprint for change program Nov 2014 by novonordisk. Available from: https:www.novonordisk.com

10. First diabetes prevalence study in Portugal : PREVADIAB study - Gardete-corrieaL ${ }^{1}$, Boavida JM, Raposo JF, Mesquita AC, Fona C, Carvalho R, Massano-Cardoso S. Available form: https://www.ncbi.nlm.nih.gov>pubmed

11. Atlas diabetes south America. Available from: https://www.slideshare.net/Pathyluna/atlas-diabetes-southamerica

12. Diabetes care in Brazil -Annals of global health. volume 81, issue 6 nov-dec 2015. Available from: www.science direct.com $>$ article $>$ pii
13. Diabetes care in Venezuela. nieto.martine $>$ R, et al. Ann Glob Health.2015 Nov-Dec. Available from: https://www.ncbi. nlm.nih.gov/pubmed/27108145

14. Atlas-data: World Health Organisation(WHO). Available from: www.who.int $>$ globalatlas.-

15. American diabetes association. Diabetes in African American community advocacy fact sheet. Available from: main.diabetes.org $>$ dorg $>$ pdfs $>$ factsheet-advocacy-africanamerican.pdf.

16. Diabetes Australia. Available from https://www.diabetes australia.com.au/diabetesinaustralia

17. Diabetes: the silent pandemic and its impact on Australia. Available from: https://statistics.diabetesau.com.au /statstics/fileassests/data.australia.

18. Diabetes facts-Australian diabetes council. Available from: https://www.diabetesaustralia.com.au/diabetesfactsaustralia.

19. World Health Organization(WHO). Rate of diabetes in china "explosive". Available from: www.wpro.who.int/china/ mediacentre/releases/2016/20160406/en/

20. World Health Organisation(WHO). Noncommunicable disease(NCD)country profile. Available from: www.who.int/nmh/publications/ncd-profiles-2014/en/

21. ICMR-India Diabetes (India) study phase-1 final report (2008-2011). Available from: icmr.nic.in/final/ indinab/indinab.ntm

22. Cases of Diabetes-Environment Portal. Government of India, Ministry of health and family welfare. Available from: https://www.indiaenvironmental.org.in/files.

\section{Cite this article as:}

Vijaya Lakshmi P \& Sudheerbabu I. Global statistical analysis of diabetes mellitus with stress on prevalence in Asia and specifically India: A critical and clinical overview. Int. J. Res. Ayurveda Pharm. 2018;9(3):58-65 http://dx.doi.org/10.7897/ 2277-4343.09363

Source of support: Nil, Conflict of interest: None Declared

Disclaimer: IJRAP is solely owned by Moksha Publishing House - A non-profit publishing house, dedicated to publish quality research, while every effort has been taken to verify the accuracy of the content published in our Journal. IJRAP cannot accept any responsibility or liability for the site content and articles published. The views expressed in articles by our contributing authors are not necessarily those of IJRAP editor or editorial board members. 